\title{
Study of Locus of Control in Female and Male MSc Students
}

\author{
Vahideh Fatemi $^{1 *}$, Dr Simin Hoseiniyan ${ }^{2}$
}

\section{ABSTRACT}

The locus of control reflects whether individuals attribute their success and failure to their own behaviors (internal locus of control) or other people or luck (external locus of control). This study attempted to study locus of control among university students. The population included a total of 6,110 incoming master's students at 10 major universities across Tehran. The sample consisted of 360 subjects selected randomly from 5 universities. The data were collected through Rotter's Locus of Control Scale (RLCS). The data were analyzed through descriptive and inferential statistical measures (Pearson correlation, T-test). Individuals with external locus of control tend to be less certain about their ability to influence the future events. One of the important outcomes associated with internal and external locus of control is self-esteem. Any success attributed to external factors such as luck or help from others can create a sense of pride and confidence. The obtained results showed that locus of control was more internalized in male students than in female students. The results further revealed that male students attributed their successes to themselves and considered external factors to be responsible for their failure. However, the results indicated that the opposite was true about the female students since they would assume responsibility for the negative consequences of their actions. According to our results, male students had confidence in their abilities, whereas female students, due to their inbred lack of self-confidence, would constantly wait for confirmation of their actions from their environment.

Keywords: Locus Of Control, Male And Female Students, Psychology.

It refers to the extent to which a person believes that they can affect their life. In terms of attributing successes or failures individuals are divided into two groups: 1) those usually attributing their success or failure to their own behavior (effort or ability), 2) those usually attributing their success or failure to luck or difficulty of tasks. People in the first groups believe they can control the outcomes, finding themselves effective in their own destiny and assume responsibility for the consequences of their behavior, whereas people in the second group

\footnotetext{
${ }^{1}$ Graduate of Khatam University, Tehran, Iran

${ }^{2}$ Science Committee of Al-Zahra University, Tehran, Iran

*Responding Author

(C) 2016 I V Fatemi, S Hoseiniyan; licensee IJIP. This is an Open Access Research distributed under the terms of the Creative Commons Attribution License (http://creativecommons.org/licenses/by/2.0), which permits unrestricted use, distribution, and reproduction in any Medium, provided the original work is properly cited.
} 


\section{Study of Locus of Control in Female and Male MSc Students}

imagine they have little control on what happens to them and ascribe the responsibility of outcomes to external factors. These individuals are known to have external control (Schultz, 1990). This approach was first proposed by Rotter in his studies on social learning in 1954. Research also revealed the significantly positive effect locus of control on the ability to learn (Gökçearslan and Alper, 2015).

With respect to school assignments and homework progress known as academic achievement, locus of control is considered a key parameter. The vast majority of research in this regard suggest that people with internal locus of control have always demonstrated better academic achievement, more efficient taking advantage of social failures and ultimately greater success in educational contexts. Conversely, those with external locus of control perform poorly throughout education (Biabangar, 1991).

In general, the literature review on indicated that the children's parents and their social position affect how locus of control develops. In fact, children will develop internal locus of control the family strengthens independent individual activities. Conversely, children will develop lower self-confidence if parents never give them opportunities to make decisions and act independently. This will lead to a fragile personality incapable of carrying tasks desirably. Such individuals inevitably surrender and tend to explain their failures through projection and defense mechanisms. In fact, they attribute their failure to factors other than themselves. The habitual adoption of this defense mechanism will become an integral part of personality.

An individual with internal locus of control tends to be mentally healthier than an individual with external locus of control. Mental health professionals believe that internal locus of control provides one of the safest strategies to combat stress. Researchers believe that individuals with internal locus of control in the workplace more easily harness their behavior, appear socially and politically more active, make an effort to influence the behavior of others and care a lot about their progress, prosperity and attaining personal goals. An individual with external locus of control, however, tends to be supervised stringent, dominant managers. Such individuals are easily affected (Ganji, 2000). Ferez (1976) reported that individuals with external locus of control tend to have greater anxiety and lower compared confidence than those with internal locus of control.

Quoted by Qasemi (1996), Hersh and Scheible (1967) found that people with internal locus of control enjoy greater containment, socialization, wisdom, patience and health than those with external locus of control. Quoted by Biabangar (1991), Joe (1972) concluded that individuals with external locus of control, unlike people with internal locus of control, tend to be more anxious and aggressive, and have lower self-esteem. Quoted by Qasemi, Dewiles and Walston (1982) reported a positive correlation between belief in external locus of control, randomness of events and the influence of authority and high scores in the depression questionnaire achieved by patients with epilepsy. According to the Wiener (1971), the individual belief in inability to 


\section{Study of Locus of Control in Female and Male MSc Students}

control events leads to depression and unfavorable psychological conditions. One of the reasons for severe depression after acute diseases such as heart attack is that the person feels there is no control over life. The same characteristics can be found in people who have external locus of control and believe there is little control over events (Mirhashemian, 1998). There is a significantly positive correlation between internal locus of control, high academic achievement and motivation (Sheikhi Moeini, 1993; quoted by Mirhashemian, 1998). In their study, Giffor, Kallen, Popowich and Powell (1990) stated that locus of control plays an important role in the development of self-esteem. This implies that people with internal locus of control enjoy higher self-esteem, maturity and positive perceptions about themselves. In their study, Karnes and Mcginis (1995) concluded there is a significantly positive correlation between age and internal locus of control. Moreover, there was a positive correlation between self-actualization and locus of control, i.e. self-actualized people have internal locus of control (Mirhashemian, 1998). Barzohar, Cooper, Findly (1988) demonstrated that students with internal locus of control enjoy more academic achievement and progress than students with external locus of control (Barron, 1991).

A series of studies focused on the correlation between self-esteem and locus of control (Rotter's theory). The previous studies in this field have unanimously highlighted the correlation between high self-esteem and internal locus of control. According to a fundamental research, it was found that there is a positive correlation between high self-esteem and internal monitoring position. These factors help individuals treat their successes and failures more desirably (Barron, 1991). In their extensive research, Comormit et al. (1977) found that subjects possessing high self-esteem tend to have internal monitoring positions, while subjects with low self-esteem tend to have external monitoring positions (Biabangarn, 1991). Ostadi (1995) carried out a study on 300 fourth grade high school students in Tehran, indicating that there is a significantly inverse correlation between irrational beliefs and self-esteem. In fact, an increase in the subjects' irrational beliefs led to lower self-esteem and vice versa. The relevant studies either inside or outside Iran revealed there is a correlation between self-esteem and locus of control. In fact, high self-esteem is associated with internal locus of control and consequently greater performance in different areas. According to the research objectives, the following hypotheses were tested: 1) there is a correlation between self-esteem and locus of control, 2) Self-esteem is lower in girls than boys. 3. Locus of control is different for boys and girls.

\section{METHODOLOGY}

This was an ex post facto, causal-comparative research. The population comprised a total of 6,110 master's students at major universities across Tehran, including Alzahra University, Amir Kabir University, Tarbiat Modares University, University of Tehran, K. N. Toosi University of Technology, Shahid Beheshti University, Sharif University of Technology, Allameh Tabataba'i University and Iran University of Science and Technology. The sample was selected randomly. At first, 5 out of 10 universities were randomly selected to be Alzahra University, Amir Kabir University, University of Tehran, Shahid Beheshti University and Allameh Tabataba'i 


\section{Study of Locus of Control in Female and Male MSc Students}

University. There were a total of 3,613 incoming students in the first semester at the five universities. The sample size was calculated to be 360 based on Morgan's table. The data were collected through Rotter's Locus of Control Scale (RLCS).

Rotter's Locus of Control Scale (RLCS): Containing 29 items each involving a pair of (a) and (b) questions, the RLCS has been devised to measure the individual expectations about locus of control. The subjects were asked to check one of the questions in each item. Clearly, the choice will depend on the subject's deep conviction.

Rotter formulated 23 items within this questionnaire to determine individual expectations about locus of control, while the remaining neutral items pursue the test objective in disguise by obscuring the assessment structure and dimension. The subjects were scored based on the total scores achieved by responding to the items. Reflecting the degree of control, the sum of scores exclude the neutral items. As for the 23 main items, the (a) questions were assigned 1 point while (b) questions were assigned 2 points. Since each person's total score is indicative of the type and degree of locus of control, only the subjects scoring 9 or higher will have external locus of control, whereas those scoring less will have internal locus of control.

\section{FINDINGS}

\section{Section one: Overview and analysis of results}

Revolving around the analysis of data, this section will explore the key descriptive statistics employed in this study. At first, there are several tables and figures illustrating the findings. The key components in this section were self-esteem, locus of control and parental education.

\section{A) Locus of control in boys}

Table 1: Distribution and frequency of locus of control among boys

\begin{tabular}{|l|l|l|}
\hline Index & Frequency & Frequency percentage \\
\hline 5 & 20 & 11.1 \\
\hline 6 & 22 & 12.2 \\
\hline 7 & 32 & 17.8 \\
\hline 8 & 39 & 21.7 \\
\hline 9 & 18 & 10 \\
\hline 10 & 20 & 11.1 \\
\hline 11 & 17 & 9.4 \\
\hline 12 & 8 & 4.4 \\
\hline 13 & 4 & 2.2 \\
\hline Total & 180 & 100 \\
\hline
\end{tabular}


Figure 1: Frequency percentage of locus of control among boys

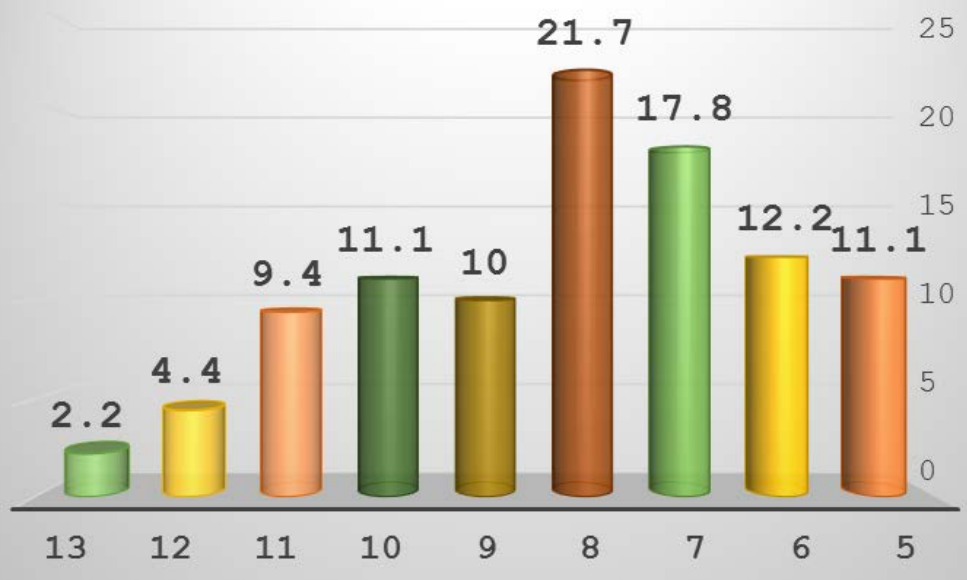

The data in Table and Figure 1 represent the lowest score was 13 and the highest score for locus of control was 13. Moreover, the most frequent score was 8 . The mean score was 8 and the median was 8.14.

Table 2: Frequency percentage of locus of control 2 among boys

\begin{tabular}{|l|l|l|}
\hline Index & Frequency & Frequency percentage \\
\hline Internal & 112 & 62.2 \\
\hline External & 68 & 37.8 \\
\hline Total & 180 & 100 \\
\hline
\end{tabular}

In Table 2, the internal and external locus of control have been divided into two segments, representing that $62.2 \%$ of the male students had internal locus of control while $37.8 \%$ had external locus of control. The mean score was 1 and the median was 1.38 .

B) Locus of control in girls

Table 3: Distribution and frequency of locus of control among girls

\begin{tabular}{|l|l|l|}
\hline Index & Frequency & Frequency percentage \\
\hline 4 & 1 & 0.6 \\
\hline 5 & 16 & 8.9 \\
\hline 6 & 12 & 6.7 \\
\hline 7 & 19 & 10.6 \\
\hline 8 & 26 & 14.4 \\
\hline 9 & 21 & 11.7 \\
\hline 10 & 19 & 10.5 \\
\hline 11 & 23 & 12.8 \\
\hline
\end{tabular}




\begin{tabular}{|l|l|l|}
12 & 19 & 10.5 \\
\hline 13 & 12 & 6.7 \\
\hline 14 & 8 & 4.4 \\
\hline 15 & 4 & 2.2 \\
\hline Total & 180 & 100 \\
\hline
\end{tabular}

Figure 2: Frequency percentage of locus of control 2 among girls

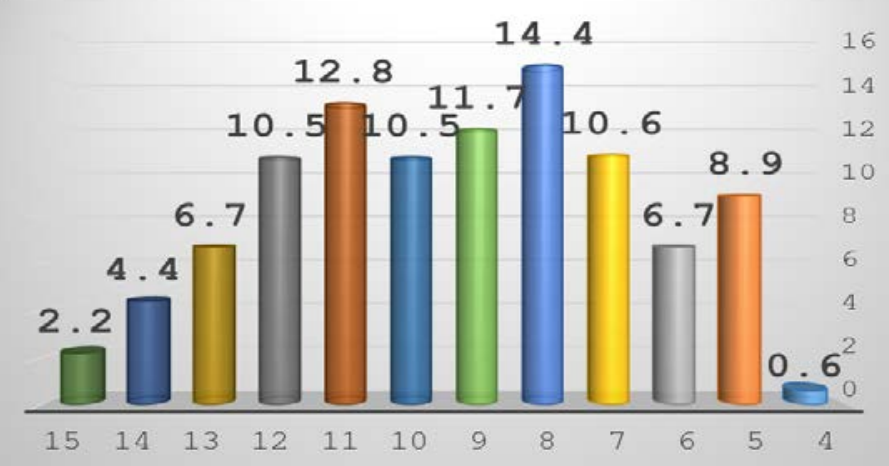

Based on the data in Figure 2 and Table (3) concerning the locus of control, the most frequent score was 8 . The lowest score was 4 while the highest score was 15 . The mean score was 9 and the median was 36.9 .

Table 4: Distribution and frequency of locus of control 2 among girls

\begin{tabular}{|l|l|l|}
\hline Index & Frequency & Frequency percentage \\
\hline Internal & 75 & 41.7 \\
\hline External & 105 & 58.3 \\
\hline Total & 180 & 100 \\
\hline
\end{tabular}

Table (4) have divided locus of control into internal and external reflecting the locus of control among female students. In this regard, $58.3 \%$ of students had external locus of control while 41.7\% had internal locus of control. This mean value was 2 and the median was 58.1.

Part two: Description and analysis of data for each hypothesis

The most important statistical test employed in this study was Pearson correlation coefficient for calculating the level and locus of control among students. Moreover, the significant results were used to test the hypotheses. 
Hypothesis: Locus of control is different for boys and girls.

Table 5: Analysis results for variance of locus of control

\begin{tabular}{|l|l|}
\hline Mean locus of control in girls & 9.36 \\
\hline Variance of locus of control in girls & 7.18 \\
\hline Mean locus of control in boys & 8.14 \\
\hline Variance of locus of control in boys & 4.33 \\
\hline T-test & -4.81 \\
\hline Significance error & 0.000 \\
\hline Number & 180 \\
\hline
\end{tabular}

The results showed that there was more internal locus of control in boys than in girls, proving the hypothesis that locus of control differs in boys and girls at error level of 0.01 . Although the locus of control in both male and female groups tended toward internalization owing to their education, it was higher in girls.

The other findings indicated that there is a correlation between parental education, self-esteem and locus of control in girls.

Table 6: The results for the correlation between locus of control and parental education among girls

\begin{tabular}{|l|l|}
\hline Correlation coefficient & -0.543 \\
\hline Significance level & 0.000 \\
\hline Number & 180 \\
\hline
\end{tabular}

In addition, the inverse correlation between locus of control and parental education was proven at significance level of 0.01 , i.e. higher parental education leads to internalization of locus of control.

However, this correlation held true only about girls rather than boys. The results have been displayed in the following tables. 
Table 7: The results for the correlation between locus of control and parental education among boys

\begin{tabular}{|l|l|}
\hline Mean locus of control in boys & 9.36 \\
\hline Variance of locus of control in boys & 7.18 \\
\hline Mean of parental education among boys & 5.14 \\
\hline Variance of parental education among boys & 8.83 \\
\hline T-test & -0.112 \\
\hline Significance error & 0.136 \\
\hline Coefficient of variation $R^{2}$ & 0.012 \\
\hline Number & 180 \\
\hline
\end{tabular}

\section{DISCUSSION}

In this study the locus of control has been analyzed between female and male students of major universities of Tehran at MSc level. The obtained results showed that locus of control was more internalized in male students than in female students. The results further revealed that male students attributed their successes to themselves and considered external factors to be responsible for their failure. However, the results indicated that the opposite was true about the female students since they would assume responsibility for the negative consequences of their actions. According to our results, male students had confidence in their abilities, whereas female students, due to their inbred lack of self-confidence, would constantly wait for confirmation of their actions from their environment. In this regard, the influence of the Iranian society on the way locus of control is formed must be considered. It should be reminded that the females of our society unconsciously tend to seek society's confirmation of their actions because of their being more vulnerable, which leads to the externalization of locus of control. Another point concerning the effect of a society is that the facilities and conditions to achieve goals are generally made more available to men and men achieve their goals by making an effort in that direction. However, girls and women may not be provided with the same facilities that are made available to men due to the limitations imposed by society. This in turn would lead women into thinking that success is not solely achieved through personal effort. Various methods, such as biofeedback, role-playing, cognitive therapy, reality therapy, psychotherapy, etc. were created for the purpose of increasing a person's internal locus of control. 


\section{Study of Locus of Control in Female and Male MSc Students}

\section{REFERENCES}

Akbarzadeh, Nasrin, 1997, Transition from adolescence to old age, Tehran, Moalef Publications

Alizadeh, Hamid, 2003, Alfred Adler, Personality and psychotherapy theory, Tehran, Danjeh Publications

Bayanzadeh, Seyed Akbar, Monfared, Afshin Heydari, A., et al., 1999, Mental health of employees in an industrial complex, Andeisheh va Raftar Quarterly, Issue 4

Berek, J. A. , Chaiken,S. , Govender, R., \& Pratto, F. (2000). The generality of the automatic attitude activation effect. Journal of Personality Social Psychology, 62, 893-9 12

Besley. G. J (1999). Anger management: Immediate intervention by counselor coach. Journal of Professional school counseling.3(2).10-18

Buss, D.M. (2004). Evolutionary psychology: The new science of the mind (2nd ed.).Boston: Allyn \& Bacon.

Byrne, Bar Bara M. (1996). Measuring Self-concept Across the Life Span, American Psychological Association.

Eslaminasab Boroujerdi, A., 1997, Marriage Counseling, Tehran, Hayan Publications

Eslaminasab Boroujerdi, A., 2001, Secrets and strategies to better way of living, Tehran, Nasl-e No Andish Publications

Frank, James. (1998). Clinical Psychopathology: signs and symptoms in psychiatry.

Ghasemi Falavarjani, G., 2001, Discovery of secrets, Qom, Fekr Avaran Publications

Mahdavian, Camellia, 2005, Other side of success, Tehran, Ehyaye Ketab Publications

Malakpour, M., 1992, Ehsas, Tehran, Tehran University Press

Markus, H. (1980). Self-schemata and processing information about the self. Journal of Perso1ze11it.y and Social Psychology, 35, 63-78.

Marsh , Elizabeth J. (2004). Cognitive psychology. New York: Psychology Press.

Marsh , H.W.(1987). The hierarchical structure of self-concept and the application of hierarchical confirmatory factor analysis. Journal of Educational Measurement, 24, 1739.

Marsh , H.W.(1996). Theoretical Perspectives on the structure of self-concept. In B.A. Bracken (Ed), Handbook of self-concept: Developmental, social, and clinical considerations, New York: Wiley.

Maslow, Abraham, Motivation and Personality, Translator: Ahmad Rezvani, 1998, Astan Quds Publications

Mirhashemian, Homeira. (1998). "The impact of religious beliefs on development of locus of control and psychological profile among university students across Tehran.” Master’s thesis in psychology. University of Al-Zahra.

Mohammad Khani, SH, Motayee, Fereshteh, 2004, familiarity with life skills and teaching methods, Tehran, Office of Cultural Affairs Planning and Counseling, Tehran Ministry of Education.

Ostadi Moghaddam, Kazem. (1998). Soltan Eshgh. Arjomand Publications. Tehran.

Rasouli, Zainab. (2007). A study on attachment styles and locus of control with marital adjustment of clients visiting the counseling center. 


\section{Study of Locus of Control in Female and Male MSc Students}

Rogers, T. B., Kuiper, N. A., \& Kirker, W. S. (1977). Self-reference and the encoding of personal information. Journal of Personality and Social Psychology, 35, 677-688.

Sarter, Jean Paul .(1980). Tenet of psychology.

Shafiabadi, Abdullah, Naseri, G., 1986, theories of counseling and psychotherapy, Tehran, Center of Academic Publishing

Stan Hause, Glen, keys to developing self-confidence in children and adolescents, Translator: Nahid Azadmanesh, 1999, Tehran, Saberin Publications

How to cite this article: V Fatemi, S Hoseiniyan (2016), Study of Locus of Control in Female and Male MSc Students, International Journal of Indian Psychology, Volume 3, Issue 3, No. 9, DIP: 18.01.154/20160303, ISBN: 978-1-365-13820-1 